\title{
Medievalista
}

Online

$10 \mid 2011$

Número 10

\section{Duas Capelas Laterais medievais do Convento de S. Francisco de Tavira}

\section{Marco Sousa Santos}

\section{OpenEdition}

\section{Journals}

\section{Edição electrónica}

URL: http://journals.openedition.org/medievalista/207

DOI: 10.4000/medievalista.207

ISSN: 1646-740X

\section{Editora}

Instituto de Estudos Medievais - FCSH-UNL

\section{Refêrencia eletrónica}

Marco Sousa Santos, «Duas Capelas Laterais medievais do Convento de S. Francisco de Tavira ", Medievalista [Online], 10 | 2011, posto online no dia 01 julho 2011, consultado no dia 19 abril 2019. URL : http://journals.openedition.org/medievalista/207 ; DOI : 10.4000/medievalista.207

\section{(C) IEM}


Titulo: Duas Capelas Laterais medievais do Convento de S. Francisco de Tavira.

Autor(es): Marco Sousa Santos

Enquadramento Institucional: Departamento História da Arte, Universidade do Algarve

Contacto: marcosousasantos@ hotmail.com

Fonte: Medievalista [Em linha]. №10, (Julho 2011). Direc. José Mattoso. Lisboa: IEM.

Disponível em: http://www2.fcsh.unl.pt/iem/medievalista/

ISSN: 1646-740X

\section{Resumo}

Duas capelas laterais, actualmente integradas num espaço ajardinado, são praticamente tudo o que resta do antigo convento de São Francisco de Tavira, provavelmente fundado no final do século XIII, oficialmente extinto em 1834.

O propósito deste breve apontamento é, acima de tudo, chamar a atenção para a necessidade de levar a cabo um estudo mais rigoroso dos elementos formais destas duas capelas, particularmente dos símbolos heráldicos nelas existentes, alguns até agora nem sequer identificados, testemunhos ímpares da Tavira medieval. Por motivos práticos, estas capelas serão provisoriamente identificadas como capela dos Machados e capela dos Costas (numa alusão directa aos símbolos heráldicos nelas existentes), uma vez que não são conhecidas as suas designações originais.

Palavras-chave: Arquitectura Gótica, Capelas, Heráldica, Tavira 


\section{Abstract}

Two side chapels, presently integrated in a gardened space, are practically all that remains from the ancient Tavira's Saint Francis convent, probably founded in the late XIII century, officially extinguished in 1834.

The purpose of this brief note is, above all, to call attention for the need to carry on a more rigorous study of the formal elements of these two chapels, particularly the heraldic signs existing therein, some of them not even identified up until now, extraordinary testimonials from medieval Tavira. For practical reasons, these chapels will be provisionally called as Machados chapel and Costas chapel (in a direct allusion to the heraldic symbols represented there), because their primitive designations are not known.

Keywords: Gothic Architecture, Chapels, Heraldic, Tavira.

\section{Duas Capelas Laterais medievais do Convento de S. Francisco de Tavira}

\section{Marco Sousa Santos}

O convento franciscano de Tavira foi estabelecido numa zona extramuros, num local próximo às muralhas da vila, no topo de uma pequena elevação fronteira à colina genética do núcleo urbano. Apesar de não ser possível apontar uma data exacta para a efectiva fundação do convento de São Francisco, pensa-se que esta terá ocorrido entre 1272 e 1330. De facto, no ano de 1272, data em que é elaborado um rol dos conventos franciscanos sob alçada das recém-criadas custódias portuguesas de Coimbra e Lisboa, não é feita qualquer referência à existência de conventos da Ordem no Algarve; só em

Medievalista online № 10| Julho - Dezembro 2011 @ IEM - Instituto de Estudos Medievais 2 www2.fcsh.unl.pt/iem/medievalista 
1330, quando é elaborado um novo inventário, desta vez por ocasião da subdivisão da jurisdição de Lisboa em duas (Lisboa e Évora), surgem, pela primeira vez, arrolados os conventos franciscanos de Tavira e Loulé ${ }^{1}$. Segundo o cronista franciscano Frei Jerónimo de Belém, os responsáveis pela edificação de um primitivo cenóbio nesta localização teriam sido os cavaleiros Templários, e só após a extinção coerciva da Ordem do Templo, ocorrida em 1312, a Casa teria passado para as mãos dos Franciscanos claustrais ${ }^{2}$.

$\mathrm{Na}$ verdade, o mais provável é que os religiosos franciscanos tenham chegado ao Algarve logo após a conquista deste território, instalando-se nos principais núcleos urbanos, inicialmente em edifícios devolutos e, regra geral, modestos, e que só depois da autorização papal para o estabelecimento de igrejas franciscanas, no interior das quais os religiosos mendicantes podiam exercer a sua pregação, em $1312^{3}$, estes se tenham preocupado em construir edifícios cultuais próprios ou, eventualmente, em ocupar construções preexistentes.

A primitiva igreja conventual seria um edifício estruturalmente simples, como eram normalmente as igrejas mendicantes, com planta em forma de cruz latina, cabeceira de formato poligonal, duas capelas colaterais, transepto saliente, e corpo de uma ou de três naves.

A mais antiga representação da igreja do convento de São Francisco de Tavira, numa planta da cidade executada por Leonardo Ferrari no século XVII (cerca de 1645), mas a partir de um original do século $\mathrm{XVI}^{4}$, permite perceber a estrutura, externa e interna, do edifício medieval, testemunhando que se tratava efectivamente de uma igreja com

\footnotetext{
${ }^{1}$ Cf. Damião de Brito VASCONCELOS, Notícias históricas de Tavira - 1242/1840, 1999, pág. 208; Cf. Bernardo de Vasconcelos e SOUSA, Ordens Religiosas em Portugal: Das Origens a Trento - Guia Histórico, 2006, pág. 310. Não obstante, conforme defende João Miguel Simões, é preciso ter em conta que os conventos franciscanos de Loulé e Tavira podem ter sido fundados em data anterior, mais precisamente entre 1253 e 1267, por iniciativa de D. Afonso X (1221-1284), numa altura em que o monarca castelhano reclama a posse do Algarve, apesar de D. Afonso III (1248-1279) se intitular já como soberano desse território. Deste modo, a sua não inclusão no rol dos conventos existentes em território português no ano de 1272, mesmo depois do reconhecimento das pretensões do soberano português sobre o Algarve, explicar-se-ia pela manutenção da primitiva custódia sevilhana (Cf. João Miguel SIMÕES, O convento da Graça, Antigo mosteiro de São Francisco de Loulé - monografia histórico-artística, 2008, pp. 15 a 22). Note-se, porém, que actualmente não se conhece nenhum documento que suporte esta hipótese.

${ }^{2}$ Cf. Bernardo de Vasconcelos e SOUSA, Ordens Religiosas em Portugal: Das Origens a Trento - Guia Histórico, 2006, pág. 310.

${ }^{3}$ Cf. Carlos Alberto Ferreira de ALMEIDA, Mário Jorge BARROCA, História da Arte em Portugal - O Gótico, 2002, pág. 18.

${ }^{4}$ Cf. Rita MANTEIGAS, "Tavira: apontamentos para as relações com a periferia rural e vestígios da ruralidade na cidade”, 2010, pág. 101.
} 
capela-mor de formato rectangular, ladeada por duas capelas colaterais, apenas com uma nave, com três capelas laterais adossadas e, entre estas, um portal lateral. As capelas laterais não fariam parte do projecto original e terão sido acrescentadas ao edifício a partir do século XIV, numa época em que as construções das Ordens Mendicantes se tornam espaços sepulcrais privilegiados ${ }^{5}$.



Fig. 1. LEONARDO FERRARI. Pormenor da igreja do convento de São Francisco numa planta da cidade de Tavira, executada em meados do século XVII (c. 1645), a partir de um original do século XVI. Atlas del Marquês de Heliche, Arquivo Militar de Estocolmo.

Fonte digital: http://4gatos.es/editorial/atlas-del-marques-de-heliche/

Segundo se pode perceber a partir da referida planta seiscentista, no século XVI a igreja conventual contava com um total de oito capelas, identificáveis pelas mesas de altar nela representadas. Não deixa de ser curioso, e de certo modo invulgar, o facto de duas das mesas de altar, as das capelas laterais imediatamente abaixo do transepto, serem representadas em posição lateral, e não encostadas à parede testeira, isto é, não directamente em frente ao arco da capela, como seria de esperar. É possível que o facto de alguns retábulos se encontrarem em posição lateral, e não encostados à dita parede testeira, esteja relacionada com a presença de arcas tumulares ${ }^{6}$ nesse local, ocupando uma posição de destaque no interior das capelas funerárias.

${ }^{5}$ Cf. Carlos Alberto Ferreira de ALMEIDA, Mário Jorge BARROCA, História da Arte em Portugal - O Gótico, 2002, pp. 18 e 19.

${ }^{6}$ Como exemplo desta prática funerária na região do Algarve, refiram-se as arcas tumulares existentes na antiga Sé de Silves (Cf. Filipa Gomes do AVELAR, Miguel Maria Telles Moniz CôRTE-REAL, As inscrições funerárias da Sé: estudo epigráfico e biográfico dos sepultados, 2005, pp. 78 a 99) ou a capela de São Domingos, sita na igreja da Sé de Faro, onde se encontra a arca tumular com jacente de Rui Valente, membro do conselho de D. Afonso V (1438-1481) e vedor da Fazenda Real no Algarve,

Medievalista online $\mathrm{N}^{0} 10 \mid$ Julho - Dezembro 2011 ๑ IEM - Instituto de Estudos Medievais 4 
Para além disso, conforme se observa na mencionada planta de Leonardo Ferrari, no século XVI, a entrada para o templo fazia-se através de um portal lateral, virado a Norte, encaixada entre duas capelas laterais da nave, no lado do evangelho ${ }^{7}$.

Numa outra gravura, esta publicada no ano de 1843 no Jornal "O Panorama", alegadamente uma reprodução de um original quinhentista, datável de meados do século $\mathrm{XVI}^{8}$, a igreja do convento de São Francisco de Tavira é representada como um edifício de planta em cruz latina, com cobertura em telhado de duas águas, com capela-mor de terminação rectangular, rematada por grandes janelões de iluminação (intercalados por contrafortes?), sendo bem visível o braço direito do transepto, que se destaca no volume do edifício. Apesar de não serem facilmente identificáveis, são também perceptíveis os volumes que constituem as duas capelas colaterais, nomeadamente a que se encontra no lado do evangelho.

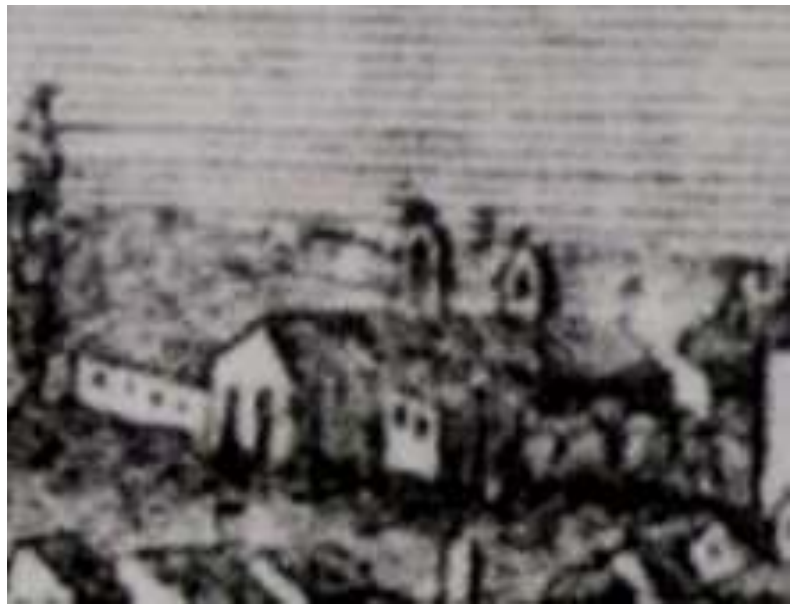

Fig. 2. Pormenor da igreja e do convento de São Francisco numa gravura da cidade de Tavira publicada no Jornal O Panorama, de 1843.

Fonte: Rita MANTEIGAS, Tavira: apontamentos para as relações com a periferia rural e vestígios da ruralidade na cidade, 2010, pág. 102

executada na década de 60 do século XV (Cf. José Custódio Vieira da SILVA, A capela de São Domingos e o monumento funerário de Rui Valente na Sé de Faro, 2006, pp. 84 a 91).

${ }^{7}$ Numa descrição publicada na revista Ocidente, no final do século XIX (1881), é explicitamente referido que a porta principal da igreja do convento de São Francisco de Tavira se achava voltada ao ocidente, acrescentando-se que a capela instituída por Lopo de Melo e sua mulher se encontrava no lugar onde constava ter sido antes a porta da igreja (Damião de Brito VASCONCELOS, Notícias históricas de Tavira - 1242/1840, 1999, pp. 209 e 210). Ou seja, em data que não é possível precisar, o portal lateral terá sido substituído por uma nova capela lateral e, provavelmente nessa altura, aberto um portal axial, virado a ocidente.

${ }^{8}$ Cf. Rita MANTEIGAS, Tavira: apontamentos para as relações com a periferia rural e vestígios da ruralidade na cidade, 2010, pp. 101 e 102. 
Na zona da nave, acopladas ao corpo da igreja, distinguem-se claramente as capelas laterais. Sobre os telhados, recortados na silhueta do convento franciscano, sobressaem dois campanários. À esquerda, na imagem, talvez comunicando com o braço esquerdo do transepto, desenvolve-se o que parece ser uma das alas conventuais.

Das várias capelas que terão existido na primitiva igreja do convento de São Francisco só restam, hoje em dia, vestígios materiais de duas.

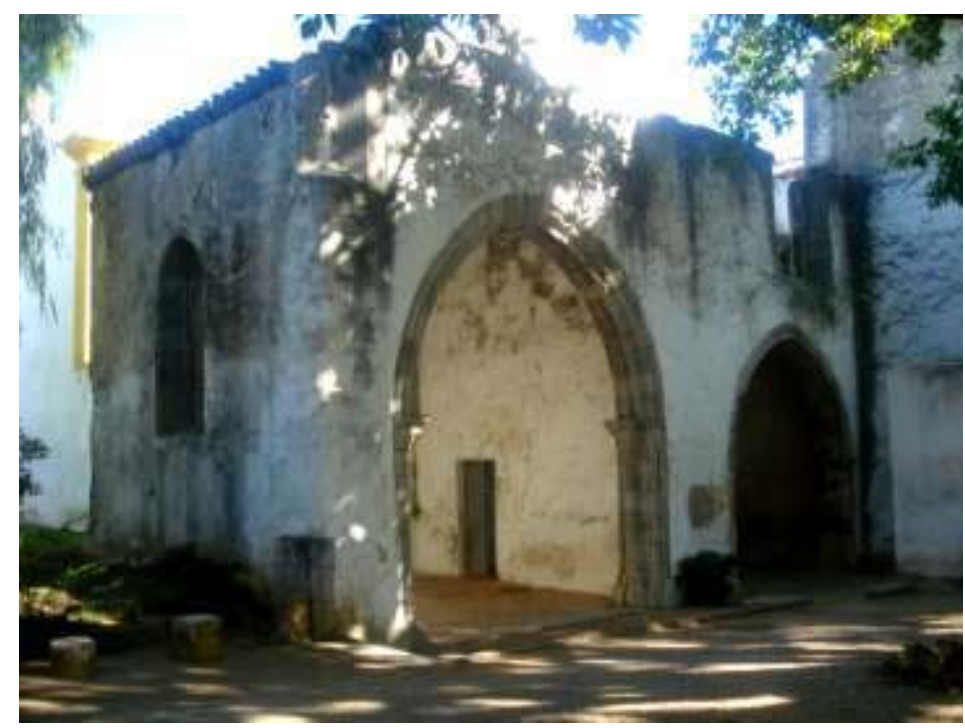

Fig. 3. Aspecto geral das duas únicas capelas laterais que restam da primitiva igreja de São Francisco de Tavira.

Foto do autor

No século XVIII, respectivamente em 27 de Dezembro de 1722 e em 1 de Novembro de $1755^{9}$, a cidade de Tavira é abalada por dois violentos sismos, dos quais terão resultado danos significativos no convento de São Francisco e, em particular, na sua igreja. De facto, em 1758, dando conta dos danos causados em Tavira pelo segundo destes cataclismos, o pároco da freguesia de Santa Maria informa que, na cidade, a maior parte dos estragos já se encontram reparados, "exceptuando o convento de São Francisco, a igreja do Hospital e a ermida de São João da Corredoura"10.

\footnotetext{
${ }^{9}$ Cf. Arnaldo Casimiro ANICA, Tavira e o seu Termo - Memorando Histórico, volume II, 2001, pág. 47.

${ }^{10}$ Idem, Ibidem, pág. 290.
} 
Em 1834, após a extinção das Ordens religiosas decretada pelo Governo liberal, e a integração dos seus bens nos Bens Nacionais, os complexos conventuais de Tavira, incluindo o de São Francisco, são levados a hasta pública. Nessa altura, as instalações conventuais, a igreja e a cerca são vendidos, separadamente, a particulares. Apenas a capela dos Terceiros, sita na igreja conventual, não é vendida, por não pertencer aos Padres franciscanos mas sim aos Irmãos da Ordem Terceira de São Francisco, em cuja posse permaneceu. A cerca do convento foi adquirida por José Pedro de Jesus e a igreja (com excepção da capela dos Terceiros), foi comprada por José Nicolau de Melo. Mais tarde, por volta de 1850, o mesmo José Nicolau de Melo vende a sua parte da igreja à Ordem Terceira, que passa assim a estar na posse de todo o edifício ${ }^{11}$.

No início de $1843^{12}$, provavelmente ainda como consequência dos danos estruturais causados pelos terramotos de 1722 e 1755, parte da nave da igreja do extinto convento de São Francisco desaba, juntamente com um trecho das antigas instalações conventuais. A Ordem Terceira toma a decisão de reconstruir o edifício mas, nessa altura, a orientação da primitiva igreja medieval é radicalmente alterada, abrindo-se a porta principal onde outrora estivera o altar da capela-mor, e passando esta a funcionar na capela dos Terceiros ${ }^{13}$, isto é, no topo do braço direito do transepto, que assim passa a desempenhar as funções de nave. Em resumo, a reorientação do edifício terá implicado o abandono da área anteriormente ocupada pela nave da igreja conventual, a transformação do antigo transepto em nave e a abertura de um novo portal, lateral, virado a Oriente.

Pouco tempo depois, logo em 1844, a Câmara Municipal de Tavira adquire o terreno onde se situavam as ruínas da nave da antiga igreja conventual, com o propósito de nele instalar um cemitério público ${ }^{14}$. É provável que então se tenha procedido ao derrube

\footnotetext{
${ }^{11}$ Cf. Arnaldo Casimiro ANICA, Tavira e o seu Termo - Memorando Histórico, volume II, 2001, pág. 100. A partir desta altura, a antiga igreja do convento de São Francisco de Tavira passa a ser designada como igreja da Ordem Terceira de São Francisco.

${ }^{12}$ Idem, Ibidem, 2001, pág. 100.

${ }^{13}$ Damião de Brito VASCONCELOS, Notícias Históricas de Tavira (1242/1840), 1999, p. 210. Note-se que a actual orientação da igreja da Ordem Terceira de São Francisco resulta de uma segunda reorientação do edifício, levada a cabo já no final do século XIX, uma vez que, em Março de 1881, um raio cai sobre esta igreja, incendiando a capela dos Terceiros e provocando danos importantes no resto do edifício. Na sequência da destruição causada pelo dito incêndio, a orientação da igreja volta a ser alterada, abrindo-se uma nova porta principal, virada a Norte, no sítio onde até aí existira a sua capela privativa (que funcionava como capela-mor) e transferindo-se o altar-mor para o extremo oposto do edifício (Cf. Arnaldo Casimiro ANICA, Tavira e o seu Termo - Memorando Histórico, volume II, 2001, pág. 101).

${ }^{14}$ Arnaldo Casimiro ANICA, Tavira e o seu Termo - Memorando Histórico, volume II, 2001, pág. 161.
} 
controlado do que restava da nave da antiga igreja medieval, optando-se por conservar apenas duas das suas capelas laterais, certamente os elementos estruturais menos afectados pela derrocada de 1843 .

Após 1918, data em que é desactivado o cemitério municipal de São Francisco ${ }^{15}$, o espaço onde outrora se erguera a nave da igreja medieval (da qual restavam apenas as duas capelas laterais), acaba por ser transformado em viveiro municipal e, posteriormente, em jardim público.

\section{A Capela dos Machados ${ }^{16}$}

Pensa-se que esta capela, a mais antiga das duas que subsistem, terá sido construída ainda no final do século XIV $^{17}$. Originalmente adossada à parede Norte da nave da igreja do convento de São Francisco, com a qual comunicava através de um arco apontado, confinava a Este com o transepto e a Oeste com a outra capela semelhante, a dos Costas, comunicando com esses espaços através de passagens abertas nas suas paredes laterais.

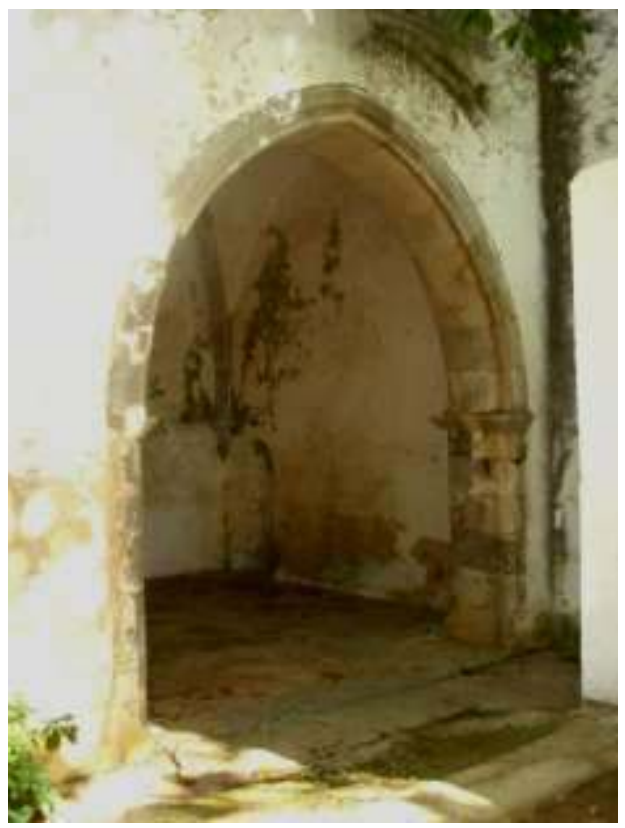

Fig. 4. Aspecto geral da Capela “dos Machados".

Foto do autor

${ }^{15}$ Idem, Ibidem, pág. 162.

16 Esta denominação é atribuída apenas com base na existência de representações escultóricas de machados, cuja utilização se repete no arco da capela e na pedra de fecho da sua abóbada, e servirá apenas para mais facilmente identificar a referida capela no decorrer deste trabalho.

${ }^{17}$ Pedro DIAS, A arquitectura gótica em Portugal, 1994, pág. 149. 
O arco de entrada da capela dos Machados é constituído por duas pilastras, com formato rectangular e ângulos cortados (chanfrados). No topo destas pilastras, que constituem o corpo inferior do arco, foram escavados orifícios, de formato semelhante e colocados à mesma altura, que poderão ter servido para fixar algo, eventualmente uma grade que limitasse o acesso ao interior da capela. Sobre as pilastras assentam impostas, e não capitéis, que servem de arranque ao arco apontado, tipicamente gótico, formalmente muito elementar, com arquivoltas e intradorso sem qualquer decoração associada. Junto à base do arco, nos ângulos das pilastras, há representações de objectos do quotidiano, elementos vegetalistas e zoomórficos, podendo identificar-se um machado e um réptil (lagarto?). Para além disso, no ângulo de uma das pilastras (a do evangelho), a meia altura, está representado um outro machado, em tudo idêntico ao atrás referido. É possível que estes elementos figurativos, representados no portal de acesso à capela, tenham um carácter apotropaico, isto é, de protecção ao espaço sagrado.

Numa das pilastras deste arco (do lado do evangelho), junto à base da mesma, existem ainda duas inscrições, bastante deterioradas, compostas por caracteres góticos. Estas inscrições, sobrepostas, aparentemente abreviaturas de nomes próprios e de apelidos são, muito provavelmente, contemporâneas da construção da capela, isto é, datáveis de finais do século XIV. Tendo em conta a posição em que se encontram, no arco de entrada da capela, mas junto à base, é possível que se tratem das "assinaturas" dos mestres pedreiros responsáveis pela construção da mesma. $\mathrm{Na}$ primeira delas, precisamente a que se encontra mais próxima da base, é identificável a abreviatura do nome próprio Álvaro (alv ${ }^{\circ}$ ), seguida por uma inscrição de interpretação mais duvidosa, talvez a abreviatura do apelido Martins (miz). Já na segunda epígrafe é reconhecível a abreviatura do nome próprio Vasco $\left(\mathrm{v}^{\mathbf{o}}\right)$, também ela seguida pelo que parece ser a abreviatura do apelido Martins (miz). 

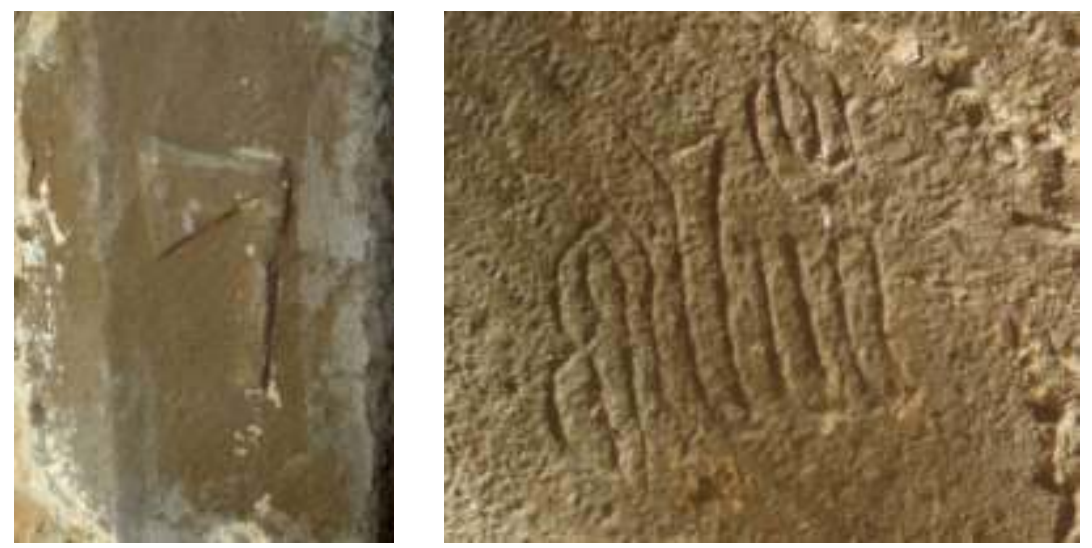

Fig. 5. Representação de um machado no ângulo da pilastra do arco da capela "dos Machados" (evangelho). Foto do autor
Fig. 6. Abreviatura do nome próprio Álvaro $\left(\mathrm{alv}^{\mathrm{o}}\right)$ inscrita na pilastra do arco da capela "dos Machados" (evangelho).

Foto do autor

A cobertura da capela dos Machados é constituída por uma abóbada de cruzaria quadripartida, com arcos que arrancam de mísulas decoradas com motivos vegetalistas, e rematada por um lanternim de iluminação ${ }^{18}$.

$\mathrm{Na}$ pedra de fecho desta abóbada está representado, no interior de um escudo, um machado, ladeado pelo que parecem ser dois pares de varas, elementos certamente invocativos do primitivo instituidor da capela. Contudo, do ponto de vista heráldico, a referida representação não parece estar directamente relacionada com nenhuma família portuguesa conhecida, uma vez que os seus elementos não correspondem às insígnias oficialmente atribuídas a nenhuma delas. Poderá eventualmente tratar-se de um símbolo pré-heráldico, isto é, de um emblema adoptado em época anterior ao estabelecimento de normas rígidas na armaria nacional, de um símbolo heráldico de origem não-nacional, ou simplesmente de uma variante medieval das armas da família Machado ${ }^{19}$ e, nesse

\footnotetext{
${ }^{18}$ Este lanternim constitui certamente um acrescento arquitectónico tardio, tendo provavelmente sido construído já no século XVII ou XVIII, com o objectivo de aumentar a luminosidade no interior da capela.

19 As armas "antigas" dos Machados são:"de vermelho, com três machados de prata; bordadura cosida de vermelho carregada de nove torres de ouro. Timbre: dois machados do escudo, passados em aspa. As armas ditas "modernas" desta família são: de vermelho, com cinco machados de prata, encabados de ouro, postos em pala e dispostos em aspa. Timbre: dois machados do escudo, passados em aspa" (Manuel de SOUSA, As origens dos apelidos das Famílias Portuguesas, 2002, p. 89). A presença de membros da família Machado em Tavira apenas está documentada a partir do século XIV, nomeadamente através de Estêvão Machado, vereador da Câmara no ano de 1499 (Arnaldo Casimiro ANICA, Tavira e o seu Termo - Memorando Histórico, volume I, 1993, pág. 386).
} 
caso, talvez um exemplo de "armas falantes", isto é, de armas em cuja representação gráfica se alegoriza o vocábulo que serve de apelido.

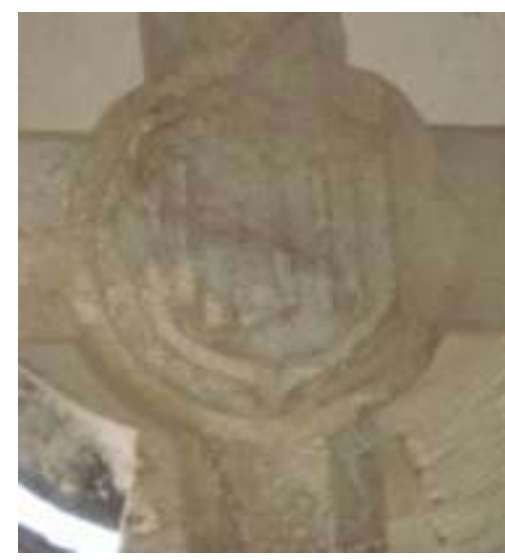

Fig. 7. Pedra de fecho da abóbada da capela "dos Machados". Foto do autor

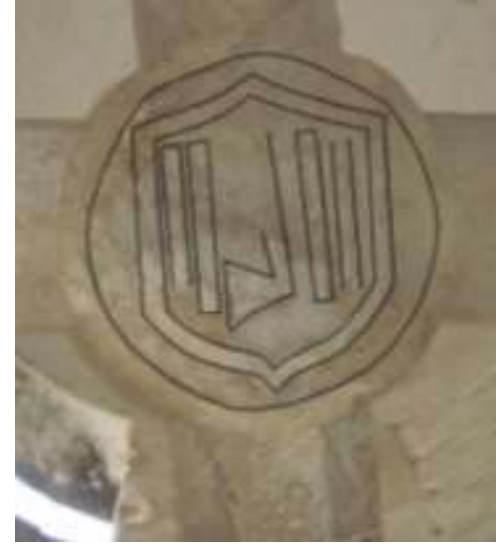

Fig. 7.1. Pedra de fecho da abóbada da capela "dos Machados".

Foto digitalmente modificada pelo autor de modo a salientar os vestígios escultóricos identificáveis

\section{A Capela dos $\operatorname{Costas}^{20}$}

A capela dos Costas confinava a Sul com a nave da igreja conventual, a Este com a capela dos Machados, com a qual comunicava através de uma passagem aberta na sua parede lateral, e a Oeste com o espaço livre onde se abria o portal lateral do templo. Apesar de não subsistirem vestígios do dito portal, a existência de uma janela geminada, caracteristicamente gótica, na parede virada a Poente, permite afirmar que esta era, de entre as capelas laterais existentes no lado do evangelho, aquela que antecedia o espaço consagrado ao portal principal (lateral) da igreja conventual medieval.

$\mathrm{O}$ arco de acesso à capela dos Costas, consideravelmente mais alto que o arco da capela vizinha, é constituído por colunelos de fuste cilíndrico, três de cada lado, com intercolúnios côncavos, bases poligonais, multifacetadas, e capitéis decorados com

\footnotetext{
${ }^{20}$ Esta denominação é atribuída apenas com base na representação heráldica existente na pedra de fecho da abóbada (um escudo esquartelado onde se distinguem claramente, entre outras de mais difícil interpretação, as armas da família Costa), e servirá apenas para mais facilmente identificar a referida capela no decorrer deste trabalho.
} 
representações de motivos vegetalistas e objectos do quotidiano. Sobre os capitéis assentam impostas, escalonadas e sem qualquer decoração associada, a partir das quais arranca o arco, alto e apontado, constituído por arquivoltas múltiplas. Tal como acontece na capela dos Machados, também os colunelos que constituem o corpo inferior do arco desta capela apresentam frestas escavadas (particularmente evidentes nas bases), que poderão ter servido para encaixar uma grade que limitasse o acesso ao interior da capela.

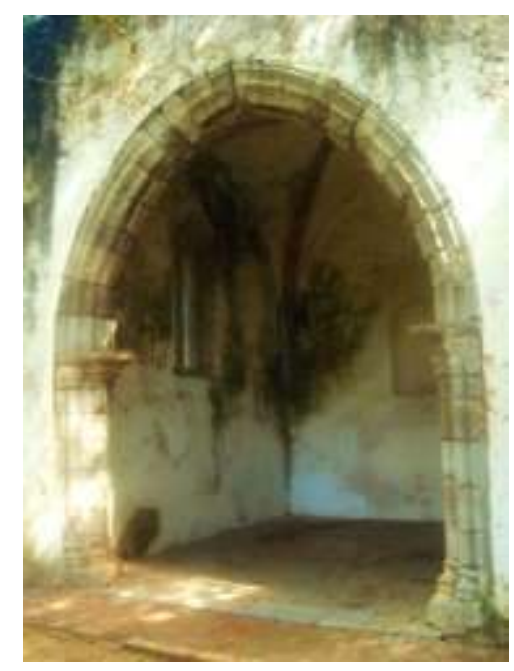

Fig. 8. Aspecto geral da capela "dos Costas".

Foto do autor

No que respeita à decoração dos capitéis, merecem particular atenção as representações de elementos associáveis ao apóstolo Santiago e ao seu culto ${ }^{21}$ : uma vieira, num dos capitéis do lado do evangelho, e duas cabaças, na epístola. É provável que estes elementos, usualmente associados a romeiros e peregrinos, façam parte de um programa decorativo deliberado, especialmente encomendado pelo primitivo instituidor da capela. Entre os demais elementos representados, todos de carácter vegetalista, é ainda possível identificar representações de romãs, também intimamente associadas ao imaginário cristão.

${ }^{21}$ Carla Varela FERNANDES, “(Des)contextos da arte Gótica em Tavira”, in Tavira, Território e Poder” (catálogo da exposição), 2003, pp. 208 e 209. 
A cobertura da capela dos Costas, em tudo semelhante à vizinha capela dos Machados, é constituída por uma abóbada com cruzaria quadripartida, com arcos que arrancam de mísulas facetadas, sem qualquer decoração associada.

Esta capela lateral desempenhou originalmente funções funerárias, funcionando como jazigo familiar e tendo provavelmente sido pensada para albergar o túmulo ${ }^{22}$ do seu instituidor, cujas armas poderão ser as que estão gravadas na pedra de fecho da sua abóbada. Apesar de não ser possível identificar, indubitavelmente, a totalidade dos símbolos heráldicos representados neste brasão esquartelado, devido ao acentuado desgaste da cantaria, não restam dúvidas que no $1^{\circ}$ e $4^{\circ}$ quartel estão figuradas as características armas da família Costa, seis costas de prata postas em três faixas e dispostas em duas palas ${ }^{23}$. O $2^{\circ}$ quartel é totalmente preenchido pelo que parece ser uma flor-de-lis e o $3^{\circ}$ por uma cruz em aspa, isto é, uma cruz cujos braços partem dos quatro ângulos do escudo, cruzando-se no centro. Particularmente no que diz respeito ao $3^{\text {o }}$ quartel deste escudo, apesar do desgaste da cantaria, que impossibilita uma identificação segura, parece haver indícios de que a referida cruz em aspa era decorada, ao centro, por uma flor-de-lis. Seja como for, não obstante as dúvidas que possam existir em relação à identificação rigorosa de alguns dos elementos heráldicos representados, dois factos, aparentemente incontestáveis, parecem resultar da análise desta pedra de armas: no $1^{\circ}$ e no $4^{\circ}$ quartel estão representadas as armas dos Costas e as armas representadas no $2^{\circ}$ quartel são distintas das representadas no $3^{\circ}$ quartel.

\footnotetext{
${ }^{22}$ É provável que, em vez de escolher para sepultura uma campa rasa, o instituidor desta capela se tenha feito sepultar numa arca tumular, como era usual no caso de indivíduos mais abastados.

${ }^{23}$ Afonso Eduardo Martins ZÚQUETE, Armorial Lusitano - genealogia e heráldica, 2000, pp. 180 e 181.
} 


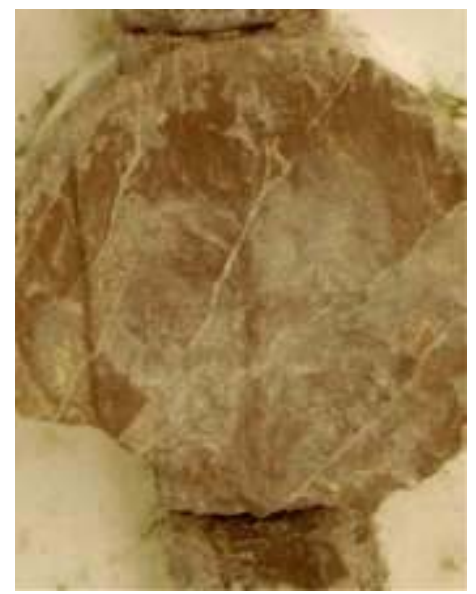

Fig. 9. Pedra de fecho da abóbada da capela "dos Costas". Foto do autor

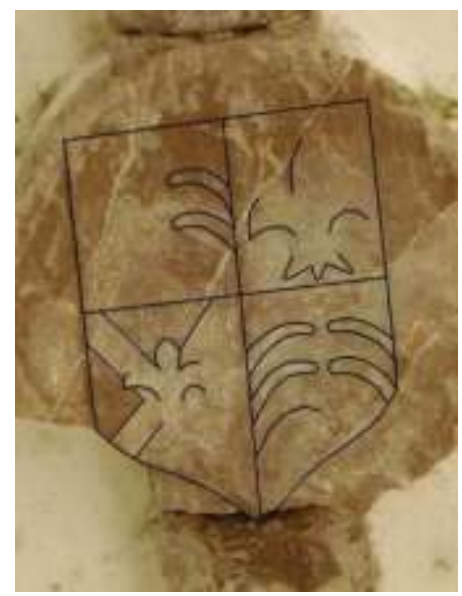

Fig. 9.1. Pedra de fecho da abóbada da capela "dos Costas". Foto digitalmente modificada pelo autor de modo a salientar os vestígios escultóricos identificáveis

Na opinião de Pedro Dias, esta capela terá sido construída já no século XV, reflectindo, por isso mesmo, a influência dos estaleiros do Mosteiro da Batalha, que se traduz sobretudo na multiplicidade de linhas utilizadas na composição do arco de entrada e no carácter tendencialmente naturalista dos seus capitéis ${ }^{24}$. Mais do que isso, a característica configuração poligonal das bases dos colunelos do arco de entrada, assim como a existência de mísulas prismáticas de ábaco facetado suportando a abóbada da capela dos Costas, em tudo idênticas às que existem no claustro afonsino da Batalha, levantado entre 1448 e $1477^{25}$, parecem apontar para a possibilidade desta capela ter sido construída na $2^{\mathrm{a}}$ metade do século $\mathrm{XV}$.

Curiosamente, há fontes documentais que fazem referência à fundação de uma capela funerária no convento de São Francisco de Tavira neste período, mais precisamente na década de 50 do século XV. Porém, os dados actualmente disponíveis não permitem perceber qual a localização exacta dessa capela, apesar de se tratar certamente de uma capela lateral. Não obstante, uma vez que em meados do século XVI só existiriam nesta

\footnotetext{
${ }^{24}$ Cf. Pedro DIAS, A arquitectura gótica em Portugal, 1994, pág. 149.

${ }^{25}$ Cf. José Custódio Vieira da SILVA, O Tardo-Gótico em Portugal - a arquitectura no Alentejo, 1989, pp. 42 e 92.
} 
igreja três capelas laterais, como se observa na já mencionada planta de Leonardo Ferrari, e tendo em conta que uma delas é a capela dos Machados, que data de finais do século XIV, parece admissível que a capela mencionada na documentação, fundada em meados do século XV, possa efectivamente ser a capela dos Costas. Todavia, a capela referida pelas fontes documentais terá sido instituída por disposição testamentária de Luís Afonso Painho, mercador, morador em Tavira ${ }^{26}$, e não por nenhum membro da referida família $\operatorname{Costa}^{27}$. Poderá, ainda assim, ser a mesma capela que até aqui se convencionou designar como dos Costas? Em termos cronológicos, e atendendo apenas às características formais da estrutura, nada impede que esta seja realmente a capela instituída pelo dito Luís Afonso Painho, mas, assim sendo, existirá uma explicação válida para a presença das armas dos Costas na pedra de fecho da sua abóbada? Vejamos:

Pouco antes de 1458, o referido Luís Afonso Painho, na altura casado com Leonor Vasques, terá mandado redigir o seu testamento, deixando instruções para que, logo após a sua morte, se instituísse no convento de São Francisco, da então vila de Tavira, uma capela por sua alma e pela de Mor Afonso, mulher com quem fora casado anteriormente $^{28}$. A dita Leonor Vasques, mulher de Luís Afonso Painho e também sua testamenteira, ficaria com o "carrego de adeficar e fazer a dita capella"29. Após a morte de Luís Afonso Painho, que terá ocorrido ainda durante esse ano de 1458, Leonor

${ }^{26}$ Cf. Ernesto do CANTO, Os Côrte-Reais: memória histórica acompanhada de muitos documentos inéditos, 1883, pp. 170. É possível que este Luís Afonso Painho, mercador, morador em Tavira, tivesse alguma relação de parentesco com Pêro Afonso Painho, também mercador, que é dos subscritores do protesto feito pelos vereadores, procurador e regedores, cavaleiros, homens bons e povo da cidade do Porto, em 11 de Junho de 1439 (Cf. António Joaquim Dias DINIS, Monumenta Henricina, Volume VI (1437-1439), 1964, pp. 325 e 329).

${ }^{27}$ Os Costas de Tavira constituem, muito provavelmente, um ramo da linhagem medieval dos Costas de Entre-Tejo-e-Odiana, família de cavaleiros e pequenos fidalgos de província cujos membros ganham notoriedade enquanto alcaides-mores de importantes núcleos urbanos como Évora e Beja (durante os séculos XIII e XIV), e que acaba por passar ao Algarve, onde adquire relevo social sobretudo através de Vasco Anes da Costa, fiel partidário do Mestre de Avis, e do seu filho Vasco Anes Côrte-Real (o primeiro a fazer uso deste apelido), que desempenha as funções de fronteiro-mor do Algarve e depois de alcaidemor de Tavira (Cf. Miguel Maria Telles Moniz CÔRTE-REAL, Fidalgos de Cota de Armas do Algarve, 2003, pág. 438). Da descendência conhecida de Vasco Anes da Costa fazem também parte, para além do já referido Vasco Anes Côrte-Real, Gil Vasques da Costa e Afonso Vasques da Costa. Sem certezas, é possível que este Afonso Vasques da Costa, filho de Vasco Anes, seja o Comendador da Ordem de Santiago na vila de Cacela e cavaleiro da Casa do Infante D. João, que é referido como procurador da vila de Tavira às Cortes de Lisboa, em 1439 (Cf. Luís Filipe OLIVEIRA, A Coroa, os Mestres e os Comendadores - as Ordens Militares de Avis e de Santiago (1330-1449), 2009, pp. 400 e 401 ).

${ }^{28}$ Cf. Ernesto do CANTO, Os Côrte-Reais: memória histórica acompanhada de muitos documentos inéditos, 1883, pág. 170.

${ }^{29}$ Idem, Ibidem, pág. 109. 
Vasques, volta a casar, desta feita com Diogo da Costa, que era irmão de Vasco Anes Côrte-Real, o qual estava casado com Mor Anes, filha da mesma Leonor Vasques ${ }^{30}$. Ou seja, Diogo da Costa $^{31}$ une-se em matrimónio com a sogra do seu irmão Vasco Anes Côrte-Real ${ }^{32}$. Ao que parece, este era já o terceiro casamento de Leonor Vasques que, para além de ter sido casada com o referido Luís Afonso Painho, fora também casada com um tal Gonçalo Gil ${ }^{33}$. Segundo sugere a documentação, Mor Anes era filha do primeiro casamento da sua mãe, isto é, de Gonçalo Gil, e não de Luís Afonso Painho ${ }^{34}$. Seja como for, mesmo após o enlace matrimonial com Diogo da Costa, Leonor Vasques não terá deixado de cumprir as disposições testamentárias do seu falecido marido. De facto, em 1469, a capela instituída por alma de Luís Afonso Painho e Mor Afonso “já era feita e hordenada e se cantava" ${ }^{35}$. Em Fevereiro de 1470 (talvez já depois da morte de Leonor Vasques), o mesmo Diogo da Costa, pede a confirmação de um documento, datado de 10 de Outubro de 1469, mediante o qual a supradita Leonor Vasques, "por seer molher e carreguava na edade e por descarreguo dallma dos ditos finados e sua „36, o nomeava como administrador interino da capela de Luís Afonso, seu defunto marido. Porém, não obstante a existência deste ajuste, o testamento de Leonor Vasques estipulava também que, após a sua morte, a administração da capela devia passar para o seu neto, na altura apenas designado como Gil $^{37}$ (Vasques da Costa), filho de Vasco Anes Côrte-Real e de Mor Anes, o que acabaria por gerar uma disputa entre os referidos

\footnotetext{
${ }^{30}$ Cf. Idem, Ibidem, pág. 113.

${ }^{31}$ Diogo da Costa, cavaleiro da Casa de D. Afonso V (1438-1481) e de D. João II (1481-1495), filho de Gil Vasques da Costa e de Dona Filipa, neto paterno de Vasco Anes da Costa. Casou, por volta de 1459, com Leonor Vasques e, depois da morte desta, com Brites Álvares, filha do Doutor Álvaro Pires Vieira, chanceler da Casa do Cível. Foi morador no arrabalde da Ribeira, em Tavira. Do seu casamento com Brites Álvares nasceria, entre outros: Francisco da Costa, o qual casou com Dona Filipa de Melo, filha de Nuno Barreto, alcaide-mor de Faro. (Cf. Ernesto do CANTO, Os Côrte-Reais: memória histórica acompanhada de muitos documentos inéditos, 1883, pp. 202 e 203)

${ }^{32}$ Vasco Anes Côrte-Real, cavaleiro da Casa de D. Afonso V (1438-1481), e seu Armador-Mor, filho de Gil Vasques da Costa e de Dona Filipa, neto paterno de Vasco Anes da Costa. Casou, antes de 1458, com Mor Anes, filha de Luís Afonso Painho e de Leonor Vasques. Do casamento de Vasco Anes com a dita Mor Anes nasceriam, entre outros, Gil Vasques da Costa e Pêro Vasques Côrte-Real. (Cf. Ernesto do CANTO, Os Côrte-Reais: memória histórica acompanhada de muitos documentos inéditos, 1883, pág. 16)

${ }^{33}$ Cf. Ernesto do CANTO, Os Côrte-Reais: memória histórica acompanhada de muitos documentos inéditos, 1883, pág. 167.

${ }^{34}$ Cf. Idem, Ibidem, pp. 16, 165, 167 e 233.

${ }^{35}$ Idem, Ibidem, pág. 170.

${ }^{36}$ Idem, Ibidem, pág. 170.

${ }^{37}$ Gil Vasques da Costa era filho de Vasco Anes Côrte-Real e de Mor Anes, neto paterno de um outro Gil Vasques da Costa e de Dona Filipa, e materno de Gonçalo Gil e de Leonor Vasques. Casou com Guiomar Serrão, de quem teve dois filhos: Tristão da Costa e Vasco Anes Côrte-Real. (Cf. Ernesto do CANTO, Os Côrte-Reais: memória histórica acompanhada de muitos documentos inéditos, 1883, pp. 15 e 16)
} 
irmãos, Diogo da Costa e Vasco Anes, respectivamente marido e genro de Leonor Vasques ${ }^{38}$. A contenda pela administração desta capela acabaria por resolver-se, ficando estipulado que o dito Diogo da Costa permaneceria como seu administrador vitalício, e que só depois da sua morte esta passaria para o mencionado Gil ou, caso este já não fosse vivo nessa altura, para um dos outros filhos de Vasco Anes Côrte-Real ${ }^{39}$.

Mas será que a administração da capela passou efectivamente para Gil Vasques da Costa, como pretendia sua avó Leonor Vasques, ou terá continuado na posse de Diogo da Costa, passando depois à descendência deste? Se a vontade da dita Leonor Vasques foi cumprida, o usufruto da capela terá acabado por passar para a posse de Gil Vasques e, eventualmente, deste para os seus filhos, Tristão da Costa e Vasco Anes Côrte-Real, havidos do matrimónio com Guiomar Serrão ${ }^{40}$. Porém, tudo indica que Gil Vasques terá falecido pouco depois do dito casamento, deixando apenas filhos menores, enquanto Diogo da Costa, que tinha o usufruto vitalício da administração da dita capela, terá vivido até à década de 80 do século $\mathrm{XV}$, uma vez que foi cavaleiro da Casa de João $\mathrm{II}^{41}$ (monarca que subiu ao trono em 1481). Deste modo, apesar de não se conhecer a data da morte de Gil Vasques, é provável que o seu tio Diogo da Costa lhe tenha sobrevivido. Há também a hipótese de, como estava previsto no testamento de Leonor Vasques, após a morte de Gil Vasques e de Diogo da Costa, a administração da capela ter passado directamente para as mãos de outro dos filhos de Vasco Anes Côrte-Real e de Mor Anes.

Após todas estas considerações, e partindo do princípio que esta é efectivamente a capela instituída por determinação de Luís Afonso Painho, subsiste uma dúvida: a quem poderão ter pertencido as armas representadas na pedra de fecho da abóbada? Seguramente que pertenceram a um indivíduo com fortes ligações à família Costa, nomeadamente por via paterna, como sugere a representação das armas desta família no $1^{\circ}$ e no $4^{\circ}$ quartel do escudo. Contudo, é pouco provável que possam ter pertencido a Luís Afonso Painho, o instituidor, já que não se lhe conhecem quaisquer ligações de

${ }^{38}$ Cf. Ernesto do CANTO, Os Côrte-Reais: memória histórica acompanhada de muitos documentos inéditos, 1883, pág. 109.

${ }^{39}$ Cf. Idem, Ibidem, pág. 109.

${ }^{40}$ Cf. Idem, Ibidem, pág. 16.

${ }^{41}$ Cf. Idem, Ibidem, pág. 202. 
sangue à referida família Costa $^{42}$. Pela mesma razão, não parece também exequível que possam ter pertencido a Leonor Vasques, responsável pela edificação da capela. Será que podem ser as armas de Gil Vasques da Costa, filho de Vasco Anes Côrte-Real e de Mor Anes? Esta hipótese justificaria, desde logo, a utilização das armas dos $\operatorname{Costas}^{43}$, que logicamente lhe pertenciam por via do dito Vasco Anes Côrte-Real, deixando em aberto a identificação das armas representadas no $2^{\circ}$ e $3^{\circ}$ quartel, que proviriam dos ascendentes de Mor Anes, sua mãe. É ainda possível que a própria Leonor Vasques, responsável pela construção, tenha antecipadamente mandado inscrever na dita pedra de fecho uma representação heráldica associável ao seu neto Gil Vasques, procurando assim garantir que a dita capela lhe seria entregue, como era sua vontade. Por último, tendo em conta que se trata de um escudo esquartelado, não será de excluir a hipótese de as referidas armas terem sido esculpidas numa época mais tardia, por um qualquer outro membro da família Costa.

Em resumo, será que a capela instituída pelo mercador Luís Afonso Painho no convento de São Francisco é a capela até agora designada como dos Costas? À luz dos factos aqui apresentados, esta hipótese parece, no mínimo, exequível. De facto, a capela dos Costas exibe características formais que apontam para uma construção datável da $2^{\mathrm{a}}$ metade do século XV, cronologicamente coincidindo com a edificação da capela de Luís Afonso

\footnotetext{
${ }^{42}$ Apesar de efectivamente não se poder estabelecer nenhuma ligação de parentesco directo entre Luís Afonso Painho e os Costas, num documento régio, datado de 30 de Junho de 1458, é feita uma referência a Vasco Anes Côrte-Real, armador-mor, e a Luís Afonso, "seu tyo" (Cf. Ernesto do CANTO, Os CôrteReais: memória histórica acompanhada de muitos documentos inéditos, 1883, pp. 162 e 163). Será que este Luís Afonso, identificado como tio de Vasco Anes Côrte-Real, é o Luís Afonso Painho que foi casado com Leonor Vasques? É possível que se trate de um erro. A verdade é que há outros documentos onde intervêm o armador-mor e o dito Luís Afonso Painho, mas a hipotética relação de parentesco entre ambos não mais volta a ser referida.

${ }^{43}$ Utilizaria Gil Vasques da Costa as armas dos Costas (de vermelho, com seis costas de prata postas em três faixas e dispostas em duas palas, firmadas nos flancos do escudo) ou as atribuídas aos Côrte-Real (de vermelho, com seis costas de prata postas em três faixas e dispostas em duas palas, firmadas nos flancos do escudo; chefe de prata, carregado de uma cruz de vermelho solta nos flancos) (Cf. Afonso Eduardo Martins ZÚQUETE, Armorial Lusitano - genealogia e heráldica, 2000, pp. 178 a 181)? Apesar de ser filho de Vasco Anes Côrte-Real, Gil Vasques não adoptou o apelido utilizado pelo seu pai, do mesmo modo que não terá utilizado as armas dos Côrte-Real mas sim as dos Costas. Para além disso, como comprovou Miguel Côrte-Real, "o uso deste sobrenome [Côrte-Real] antecedeu em cerca de um século o da respectiva heráldica" (Miguel Maria Telles Moniz CÔRTE-REAL, Fidalgos de Cota de Armas do Algarve, 2003, pág. 438). De facto, Vasco Anes Côrte-Real (bisneto paterno de Vasco Anes da Costa), Capitão donatário das ilhas de São Jorge e da Terceira, alcaide-mor de Tavira, vedor da Casa e do Conselho de D. Manuel I (1495-1521), membro do Conselho de D. João III (1521-1557), "foi o $1^{\circ}$ deste apelido a diferenciar-se heraldicamente dos outros membros da linhagem Costa a que pertencia" (Miguel Maria Telles Moniz CÔRTE-REAL, Fidalgos de Cota de Armas do Algarve, 2003, pág. 255). Ou seja, até ao século XVI, independentemente de fazerem uso do apelido Côrte-Real, ou não, os membros desta família utilizaram as armas dos Costas.
} 
Painho, que terá decorrido entre 1458 e 1469. Para além disso, encontrada que está uma ligação próxima entre o dito Luís Afonso Painho e a família Costa, torna-se igualmente admissível a presença das já referidas armas na pedra de fecho da abóbada da capela por ele instituída.

\section{FONTES DIGITAIS}

http://4gatos.es/editorial/atlas-del-marques-de-heliche/

\section{BIBLIOGRAFIA}

ALMEIDA, Carlos Alberto Ferreira de - História da Arte em Portugal - O Gótico. Lisboa: Editorial Presença, 2002. ISBN 972-23-2841-7

ANICA, Arnaldo Casimiro - Tavira e o seu Termo - Memorando Histórico. Tavira: Câmara Municipal de Tavira, 1993. ISBN 972-95007-1-1

ANICA, Arnaldo Casimiro - Tavira e o seu Termo - Memorando Histórico. Volume II. Tavira: Câmara Municipal de Tavira, 2001. ISBN 972-8705-00-X

AVELAR, Filipa Gomes do; CÔRTE-REAL, Miguel Maria Telles Moniz - "As inscrições funerárias da Sé: estudo epigráfico e biográfico dos sepultados”. In Monumentos, $n^{\circ}$ 23. Lisboa: Direcção-Geral dos Edifícios e Monumentos Nacionais, Setembro de 2005. pp. 78-99. ISSN 0872-8747

FERNANDES, Carla Varela - “(Des)contextos da arte Gótica em Tavira”. In Tavira, Território e Poder (catálogo da exposição). Tavira: Câmara Municipal de Tavira, 2003. pp. 205 a 212. ISBN 972-776-180-1 
CANTO, Ernesto do - Os Côrte-Reais: memória histórica acompanhada de muitos documentos inéditos. Ponta Delgada: Tipografia do Archivo dos Açores, 1883.

CÔRTE-REAL, Miguel Maria Telles Moniz - Fidalgos de cota de Armas do Algarve. s.l: edição do autor, 2003. ISBN 972-98874-0-3

DIAS, Pedro - A Arquitectura Gótica em Portugal. Lisboa: Editorial Estampa, 1994. ISBN 972-33-0984-X

DINIS, António Joaquim Dias - Monumenta Henricina, volume VI (1437-1439). Lisboa, 1964.

MANTEIGAS, Rita - “Tavira: apontamentos para as relações com a periferia rural e vestígios da ruralidade na cidade". In Tavira - Patrimónios da Terra (catálogo da exposição). Tavira: Câmara Municipal de Tavira, 2010. ISBN 978-972-8705-38-1

OLIVEIRA, Luís Filipe - A Coroa, os Mestres e os Comendadores: As Ordens Militares de Avis e de Santiago (1330-1449). Faro: Universidade do Algarve, 2009. ISBN 978-972-9341-80-9

SILVA, José Custódio Vieira da - O Tardo-Gótico em Portugal: a arquitectura no Alentejo. Lisboa: Livros Horizonte, 1989. ISBN 972-24-0725-2

- "A capela de São Domingos e o monumento funerário de Rui Valente na Sé de Faro". In Monumentos, n 24. Lisboa: Direcção-Geral dos Edifícios e Monumentos Nacionais, Março de 2006. pp. 84-91. ISSN 0872-8747

SIMÕES, João Miguel - O convento da Graça, antigo mosteiro de São Francisco de Loulé - monografia histórico-artística. Lisboa: Câmara Municipal de Loulé - Edições Colibri, 2008. ISBN 978-972-772-851-0

SOUSA, Bernardo Vasconcelos e (direcção) - Ordens Religiosas em Portugal: Das Origens a Trento - Guia Histórico. $2^{\mathrm{a}}$ Edição. Lisboa: Livros Horizonte, 2006. ISBN 972-24-1433-X 
SOUSA, Manuel de - As origens dos apelidos das Famílias Portuguesas. s.l.: Sporpress, Sociedade Editorial, 2002. ISBN 972-8696-01-9

VASCONCELOS, Damião Augusto de Brito - Notícias Históricas de Tavira (12421840) (anotações de Arnaldo Casimiro Anica). $3^{\text {a }}$ Edição. Tavira: Câmara Municipal de Tavira, 1999. ISBN 972-95007-5-4

ZÚQUETE, Afonso Eduardo Martins - Armorial Lusitano - genealogia e heráldica. $4^{\text {a }}$ Edição. Lisboa: Edições Zairol, 2000. ISBN 972-9362-24-6

\section{COMO CITAR ESTE ARTIGO}

\section{Referência electrónica:}

SANTOS, Marco Sousa - "Duas Capelas Laterais medievais do Convento de

S. Francisco de Tavira". Medievalista [Em linha]. Nº10, (Julho de 2011). [Consultado dd.mm.aaaa]. Disponível em

http://www2.fcsh.unl.pt/iem/medievalista/MEDIEVALISTA10lsantos1006.html. ISSN 1646-740X.

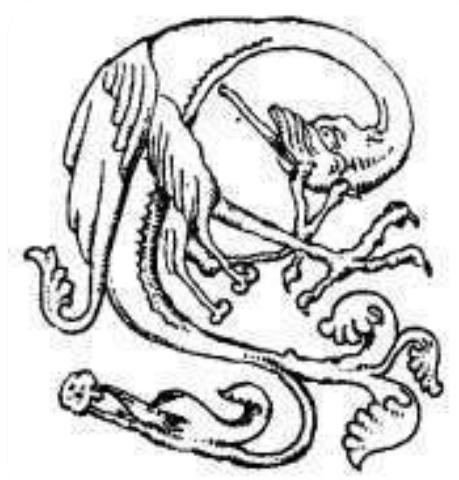

